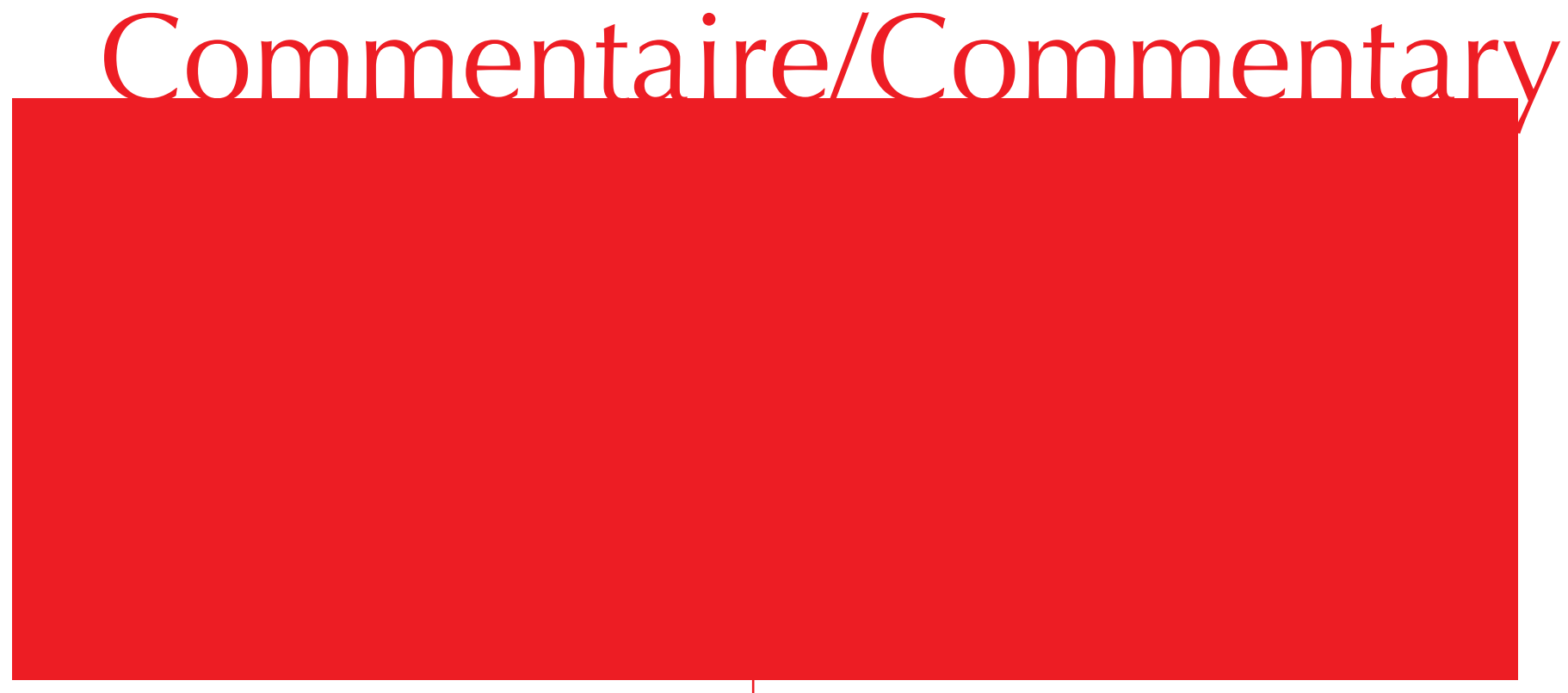

\section{Method or Madness?: The Dominance of the Systematic Review in Nursing Scholarship}

\section{ANNEMARIE JUTEL}

In 1972, Irving Zola published his seminal piece, "Medicine as an institution of social control," in the journal Sociological Review. This eloquently written article defines medicalisation and develops an explanatory theory for medicine's expanding jurisdiction and social authority in contemporary society. This piece stood in contrast to his earlier empirical social science research, interviewing attendees at the Ear Nose and Throat clinic about their presenting complaints. [1] He could not have known at the time, any more than could have his publishers, the impact that his reflections on medicalisation would have on the field. Presented differently, reflecting different methodological perspectives, both publications nonetheless contributed to furthering of the sociology of health and illness.

As the example of Zola underlines, there are many ways to advance knowledge, and scholarship takes many forms. A discipline which is generous in determining what it values as scholarship and how it can be presented is poised to embrace the novel, the exceptional and the transformative. Who would have thought, for example, that comedy might contribute to academic discussions of medicine? The benefit of hindsight shows us the importance of Leonard Stein's 1968 "Doctor-Nurse Game".[2] This text was included in a tome entitled "classic texts in health care"[3], and is cited prolifically in nursing, medical and interdisciplinary journals which explore inter-professional relationships in health. Remarkably however, this article was presented as humour, complete with cartoon caricatures of swan-necked, white-capped sisters, and eyebrow-raised, stethoscoped medical specialists throwing darts at a professional wheel of fortune. It is not alone in its genre. Richard Smith's[4] light-hearted "In search of non-disease" made important 
points about the social framing of disease which have been well-exploited by numerous academic writers since its rather recent publication.

Like humour, simple stories also deliver important truths. Arthur Frank's At the Will of the Body, an account of his personal experience of serious illness is a poignant example of scholarship through narrative. His stories and others like it now buttress a wide range of disciplinary discussions in nursing, social science and medicine. I take particular inspiration in my own work from Suzanne Fleischmann[5] and Mildred Blaxter's[6] respective (and poignant) accounts of the diagnostic trajectory in illnesses which were ultimately to prove fatal to both. They "speak" eloquently to me as nurse, as I identify with the authors' suffering, but they also highlight important critical principles like the transformative nature of the diagnostic label, and the silencing impact of diagnostic technology.

Medical journals acknowledge the importance of such stories in health care practice: Annals of Internal Medicine includes a regular doctor-as-patient stories, just as the British Medical Journal invites authors to submit stories about memorable patients, mistakes, and anything else that conveys "instruction, pathos, or humour."

Despite the example set by medicine and sociology, nursing is restricting, rather than expanding, what it allows authors to present. This is a situation which requires rapid redress. In the paragraphs to come, I will describe how the journals which stand for the mouthpiece of nursing have become overly concerned with presenting its scholarship and talking about its discipline in a standardised and exclusionary manner. This reflects a positivistic, audit-oriented belief in knowledge generation that is stymieing our profession and its scholars. This approach emerges from a devotion to evidence-based practice, and persists to the detriment of the field. An overreliance on systematic review trivialises nursing's intellectual autonomy, instead, instilling method and design into a hierarchically unjustified supreme position.

The idea of combining the results of more than one study of a similar phenomenon in order to increase their impact is at the heart of the systematic review. Early attempts at this approach were undertaken by Karl Pearson[7,8] and Ernest Jones, whose work was only "discovered" in 2003 [9] by an Anglocentric field, ignorant of Jones' publication (written in French) which reviewed material published predominantly in French and German. Ronald Fisher presented statistical techniques for using the results of independent studies to predict probabilities in 1932.[10]
But the practice did not become prevalent until the second half of the 20th century. In the late 1970s, a number of summarizing research papers were published, including Hall's[11] "Gender Effects in Decoding Nonverbal Cues," Smith and Glass'[12] "Meta-analysis of Psychotherapy Outcome Studies," and Rosenthal and Rubin's[13] summary of 345 experiments studying the tendency of researchers to obtain results they expect because of their influence in shaping responses. This study did not attempt to assess the quality of the individual experiments, rather to encompass the results of all existing studies. Their paper, they suggested, could serve as a methodological template for summarizing other entire areas of research.

Evidence based practice enhanced the prominence of this method, as both rely upon the same premises. Archie Cochrane's 1972 diatribe on Effectiveness and Efficiency is at the base of the contemporary evidence based practice movement. There, he lamented the absence of measurement of effectiveness of medical interventions and described the randomised controlled trial as a tool for "open[ing] up the new world of evaluation and control" and perhaps saving the national health service.[14]

The systematic review is "the application of scientific strategies that limit bias to the systematic assembly, critical appraisal, and synthesis of all relevant studies on a specific topic"..[15, p167] This definition emerged from the Potsdam Consultation: a consortium organised to assess and address the production of high quality meta-analysis and review of randomised controlled trials. The Potsdam Consultation developed a list of guiding principles and a methodological overview covering protocol development, search strategy, study selection, quality assessment, analysis, evaluation of heterogeneity, subgroup analyses, sensitivity analyses, presentation, interpretation, and dissemination.[15]

The over-arching theme in definitions of the systematic review is the notion that the review is a form of research itself. Webb and Roe refer to the systematic review as "Pieces of research, which aim to identify, appraise and summarise studies of relevance to a particular topic".[16] Straus and colleagues describe it as "A summary of the medical literature that uses explicit methods to systematically, search, critically appraise, and synthesize the world literature on a specific issue". ${ }^{\prime[17] ~}$

In any case, the prominence of the systematic review is buttressed by the similar prominence of evidence-based practice in clinical practice and decision-making. Yet, Goodman[7] has pointed out that there is an important tension between between efforts to make medicine more 
scientific and remain true to "clinical judgement," a tension which is present in nursing discussions of EBP. Many have railed against the prominence that the tenets of evidencebased practice have assumed in nursing. Gary Rolfe, for one, has maintained that EBP is open to many of the criticisms that it directs at other forms of knowledge generation. It lacks the "hard" evidence to support claims of its validity that it requires of other forms of practice. Evidence based practice fails to meet its own standards, "it is no more based on evidence than the forms of practice it seeks to replace" he writes .[18 p85]

Others have pointed out that evidence-based practice is the fascist imposition of a empirical project-a dominant ideology excluding alternative forms of knowledge.[19] The dominant hierarchy privileges certain kinds of research, and particular positions. Morse[20] positions EBP as a politics of ignorance-myopic and exclusionary - which uses Cochrane standards for evaluating funding for all forms of research. It is a fine sieve which ends up funding drug trials by the powerful, and relegating qualitative researchers unable to access funds, credibility, and importantly, power.

Many authors, including myself, have argued that EBP is a significant means for advancing nursing knowledge, but not one which should be used to the exclusion of all others. I have used the example of 'overweight' as a heuristic for understanding the limitation of EBP. Whilst EBP may be useful for describing epidemiological trends in $\mathrm{BMI}$, the effectiveness of interventions for reducing weight, or the correlation between overweight and other pathologies, its preferred forms of evidence can neither capture nor explain the depth and breadth of the weight loss question. It fails to demonstrate the use of weight as an unreliable proxy measure for lifestyle practices; the ethnic insensitivity of BMI and its contribution to the marginalisation of underprivileged populations; the range of commercial interests are served by the promotion of overweight-as-disease; the role of aesthetics in clinical assessment; the cultural and historical frames in which the discourse of weight is a reflection of inner character, and so forth.[21]

Despite the fact that there isn't full agreement about the place that evidence based practice should hold in nursing, it has an iron grip. And, we're not working hard enough to loosen it. This is a shame; rather than increasing nursing knowledge, EBP is replacing it, substituting its episteme for ours.

I'Il return to the review article, which is EBP par excellence, and what's more, is a perfect heuristic for recognising how we've sold out. Reviews have a constitutive role for a field.
They juxtapose, explain and analyse an assembly of related concepts which both author and publisher believe worthy of dissimilation to the discipline. They are used as research resources, teaching tools, and in the digital age, means by which journals and authors achieve notoriety. Because of their function as broad-brush summary of a topic, and subsequent utility as pedagogical aid, they result in high citation counts, which in turn result in high bibliometric ranking: a measure of status in contemporary academe. Unabashedly, most nursing journals recruit the review, knowing full-well its ability to influence the field, and reap benefits for the journal.

The review article is a criterion by which nursing defines itself and its priorities: those subjects worthy of review. In a Bourdieuan framework, the review is part of the cultural field or the "series of institutions, rules, rituals, conventions, categories, designations, appointments and titles which constitute an objective hierarchy, and which produce and authorise certain discourses and activities". [22, p21]

When one looks at the discursive construction of the review article, in any of a number of contemporary nursing journals, one is confronted by the dominant and unwavering presence of evidence based practice. Instructions to authors include the mandatory use of sub-titles such as "design," "methods," "quality appraisal," "data abstraction," "synthesis" and "results." Links to useful resources point authors exclusively to QUORUM statements, Cochrane Collaborations, EPPI, NICE and other EBP-based assessment tools. There is a salient absence of references to the academic traditions of reading and writing, promoting the systematic review as the standard to which nursing authors should aspire.

The language used these journals is the kind that MacLure[23] describes as a mix of scientific positivism and audit culture rhetoric, reifying the way in which texts must be approached. As MacLure so aptly represents, what is left unspoken in the discursive representation of the systematic review are the important themes of analysis and interpretation. The lexicon privileges audit over textuality, reproducibility over illumination. She describes the,

...fantasy of a text-free knowledge economy, where nuggets of evidence can be extracted from the rhetorical contaminations of persuasion, argument, justification, context and partiality that are inherent in all texts ... an ancient and persistent delusion. [23 p399]

Journal content in our discipline reflects either the supreme position of the systematic review within the profession, or more likely, the impact that journal policies have in shaping that which the profession judges worthy of publication. Journals 
have significant power to mould what they contain, even more so now in the day of manuscript management software which includes required form fields that an author cannot skip: an abstract must be structured, a method identified, an article category designated. But beyond the mechanics of manuscript control, the more powerful the journal, the more powerful its ability to influence the presentation and even the epistemologies of nursing knowledge. And, the power of the journal is also based in the review article.

With research evaluation exercises, and performance-based research funding, the impact factor of a journal (already a positivistic/problematic bibliometric category) constitutes its cultural capital. The more the journal's content is cited, the higher its impact factor. ${ }^{\text {a }}$ The higher its impact factor, the more submissions it is likely to receive, and the higher the quality of the resultant publication.

Nursing researchers become compliant docile subjects as they conform to journal standards which "other" traditional ways of treating the synthesis of research material. Reporting methodology--including tables to organise "evidence," and presenting a range of justifications of trustworthiness, from methodological algorithms to quality assessment tables, and detailed search criteria--confirms inflexible bonds within which nursing is compelling its academics to reflect.

One could argue that there's room for a traditional review within these discursive constraints. A savvy author could arrange a benign expression that would fit into the various sub-sections of the methodology and quality analysis description. This is a "narrative" review; quality appraisal can consist of "evaluating whether the material presented a cogent, supported argument for the themes it presents;" the discursive post-methods discussion can tolerate the header "results."

However, there are two reasons to reject this conformity. Firstly, there isn't room, amongst these headings, to express the things that matter. I present as an example, a review I have written for a prominent journal of sociology a few years ago.[25] I drew together therein many threads from a range of theoretical and historical perspectives to describe a nascent sub-discipline of medical sociology. I presented both a history and a platform: including classical texts, and mad ones. Mad they might have been, but the latter garnered significant popular interest, and despite (or perhaps because of) their heretics, played an important role in shaping discussions, as other scholars scuttled to respond, and set the story right. These little bits of sociological lunacy wouldn't pass quality analysis, yet explain the direction the discussion has ended up taking. It's simultaneously the heterogeneity and the similarities of the articles I bring together that create the base for my argument. When dialectic is the method, a "summary table" will capture neither content nor direction.

Secondly, conforming to the structured abstract kowtows to an unjustified technology of control. As Avis wrote "New academic identities are being created in which values such as academic independence, intellectual curiosity and expert judgement are being replaced by industriousness, rulefollowing, compliance and self-imposed endorsement of 'the hegemonic position of managers'".[23, p297]

That reviews are systematic is perhaps but one symptom in a more generalised attempt of the nursing journal to be submissive itself to what it sees as the scientific, or more precisely, the professional imperative. It is by producing and using research, wrote Fawcett, that "nursing will be able to declare its independence". $[26 \text { p39 }]^{\text {b }}$

But there's also that dogged need in the nurses' search for professionalization for them to withdraw from the Doctor Nurse game, that game where "nurse is to be bold, have initiative, and be responsible for making significant recommendations, while at the same time ... appear[ing] passive ... so as to make her recommendations appear to be initiated by the physician". [2] The professionalization of nursing has compelled nursing to consider how professional knowledge is constructed, and in the profession from whose grip they wish to escape, this is via EBP. Bonnell[27] has argued that nursing will be marginalized if it rejects the empirical, quantitative research, regardless of the legitimacy of their counter-argument.

For nursing to establish itself as a credible field it must have the means and techniques to imagine itself into existence, and then to represent, manifest and valorise itself in a consistent manner to its own members and to other fields. If EBP is our only tool, we have at stake here the survival of the field. We are at a place where we establish the credibility of our thoughts on the basis of our method, rather than of our arguments.

We would do well to seek inspiration from the publications of our medical counterparts. The Lancet devotes a sub-section to "Articles that advance or illuminate," encouraging debate and opinion via such fora as Viewpoint, Essay, Reportage, and the Departments of Medical History, Ethics, Medicine and Art, and Literature and Medicine.

As Goodman's has written: “...weighty burdens are borne by leaders and soldiers of the evidence-based movement, who, 
at great scientific and moral peril, might presume closure in complex domains, terminating debate and chilling research in cases where more debate and research are precisely what is wanted". $[7, \mathrm{p} 49]$

\section{Notes}

a. Impact factor is calculated as the number of citations in the current year to items published in the previous two years for a give journal, divided by the number of substantive articles and reviews published in the same two years in that journal.

b. It must be said that Fawcett also argued in this article for, in addition to research compliance, for "NOT [caps mine] relying on others for the knowledge which shapes our practice" : a position which should be seen to support other ways of knowing, of researching... and of undertaking reviews!

\section{References}

1. Foucault M. Colloqui con Foucault. Interview with Duccio Trombadori (Italian). Translated from Italian by R. James Goldstein and James Cascaito as Remarks on Marx (NY: Semiotext(e)); 1978. Available from URL http://www.csun. ed/ hfspc002/fouc.B4.html.

2.Eribon D. Michel Foucault. Translated by Betsy Wing. Harvard University Press, Cambridge, Massachusetts; 1991.

3.O'Farrell C. Michel Foucault. Thousand Oaks: Sage Publications, 2005.

4.Foucault M. Kant on enlightenment and revolution. Economy and Society1986;15(1):88-96.

5.Gordon C. (ed). Power/Knowledge: selected interviews and other writings 1972-1977. Michel Foucault, professor of the history of systems of thought, College De France. Brigton: The Harvester Press, 1980.

6.Foucault M. Truth and power. In P Rabinow (ed). The Foucault Reader, New York; Pantheon, 1984.

7.Gutting G. Foucault, Very Short Introductions. Oxford: Oxford University Press, 2005.

8.Dreyfus HL, Rabinow P. (eds). Michel Foucault: Beyond structuralism and hermeneutics: With an afterword by Michel Foucault. The University of Chicago Press. Chicago, 1982.

9.Foucault M. The order of things: archaeology of the human sciences. New York: Vintage Books, 1994.

10.Ball S. Introducing Monsieur Foucault. In Stephen J Ball, Foucault and education: disciplines and knowledge. London:
Routledge, 1990.

11. Mahon M. Foucault's Nietzschean genealogy: Truth, power \& the subject. New York: State University of New York, 1992.

12.Foucault M. Afterword: The subject and power. In Dreyfus HL, Rabinow P (eds). Michel Foucault, Beyond Structuralism and Hermeneutics. Chicago: The University of Chicago Press, 1982.

13. Roberts $M$. The production of the psychiatric subject: Power, knowledge and Michel Foucault. Nursing Philosophy 2005;6:33-42.

14.Beaulieu A, Gabbard D. (eds). Michel Foucault and power today: International multidisciplinary studies in the history of the present. New York: Rowman \& Littlefield Publishers, 2006.

15. Foucault M. Two Lectures. In Colin Gordon (ed). Power/ knowledge: Selected interviews and other writings 19721977. Brigton: The Harvester Press, 1980.

16.Littlejohn SW. Theories of Human Communication, Third Edition. Belmont: Wadsworth Publishing company, 1989.

17.McHoul A, Grace W. A Foucault primer: Discourse, power and the subject. New York: New York University Press, 1993.

18. Bouchard DF. editor. Michel Foucault: Language countermemory, practice, selected essays and interviews. New York: Cornell University Press, 1977.

19.Burchell G, Gordon C, Miller P. editors. The Foucault effect: Studies in governmentality - with two lectures by and an interview with Michel Foucault. Chicago: The University of Chicago Press, 1991.

20.Cooper B. Michel Foucault: An introduction to the study of his thought: Studies in religion and society. Volume 2. New York: The Edwin Mellen Press, 1981.

21.Gane M. The form of Foucault. Economy and Society 1986;15(1):110-22.

22.Kendall G, Wickham G. Using Foucault's Methods. Thousand Oaks: Sage Publications, 2003.

23. Rabinow P. The Foucault Reader. New York: Pantheon Books, 1984.

24.Sheridan A. Michel Foucault: The will to truth. London: Tavistock Publications, 1980.

25.Ceci C. Not innocent - relationship between knowers and knowledge. Canadian Journal of Nursing Research 2000; 
$32(2): 57-73$.

26.Ceci C, Mclntyre M. A 'quiet' crisis in health care: Developing our capacity to hear. Nursing Philosophy 2001; 2(2):122-30.

27.Crowe M. Discourse Analysis: Towards an understanding of its place in nursing. Journal of Advanced Nursing 2005; 51(1):55-60.

28. Holmes D, Gastaldo D. Nursing as means of governmentality. Journal of Advanced Nursing 2002; 36(6):557-65.

29.Cheek J, Rudge T. Inquiry into nursing as textually mediated discourse. In Chinn PL (ed.) Advances in methods of inquiry for nursing. Gaithersburg: Aspen Publishers, Inc., 1994; 59-67.

30.Purkis ME. The "social determinants" of practice? A critical analysis of the discourse of health promotion. Canadian Journal of Nursing Research 1997; 29(1):47-62.

31.Rudge T, Holmes D, Perron A. The rise of practice development with/in reformed bureaucracy: Discourse, power, and the government of nursing. Journal of Nursing Management 2011; 19(7):837-44.

32.Springer RA. Pharmaceutical Industry discursives and the marketization of nursing work: A case example. Nursing Philosophy 2011; 12(3):214-28.

33. Foucault M. Madness and civilization: A history of insanity in the age of reason. Translated from the French by Richard Howard. New York: Pantheon Books, 1965.

34.Foucault M. The birth of the clinic: Archaeology of medical perception. New York Pantheon Books, 1973.

35. Foucault M. Discipline and punish: The birth of the prison. New York: Pantheon Books, 1977.

36.Foucault M. The history of sexuality Volume I: An introduction. New York: Vintage Books, 1990.

37.Foucault M. Orders of discourse. Social Science Information 1970; 10(2):7-30.

38. Coveney J. The government \& ethics of health promotion: The importance of Michel Foucault. Health Education Research Theory \& Practice 1998; 13(3):459-68.

39.May T. The philosophy of Foucault. McGill-Queen's University Press. Montreal \& Kingston - Ithaca, 2006.

40.Davidson A. (ed). Michel Foucault: The birth of biopolitics. Lectures at the College De France 1978-1979. New York:
Palgrave MacMillan, 2004.

41.Springer RA. Pharmaceutical industry discursives and the subjectivities of physicians, nurses and multiple sclerosis patients: A Foucauldian dispositive analysis. Ottawa: Library and Archives Canada, 2010.

42.Cheek J. Influencing practice or simply esoteric? Researching health care using postmodern approaches. Qualitative Health Research1999; 9(3):383-92.

43.Fox-Keller E. Gender and science: Origin, history and politics. Osiris 1995; 10:27-38.

44.Davidson A. (ed). Michel Foucault: Security, territory, population. Lectures at the College De France, 1977-1978. New York: Palgrave MacMillan, 2004.

Contact Information for Author:

Annemarie Jutel, IDE, BPhEd(Hons), Ph.D.

Director of Research

Graduate School of Nursing Midwifery and Health

Victoria University of Wellington

Wellington, PO Box 7625

New Zealand

email: annemarie.jutel@vuw.ac.nz 